\title{
TINJAUAN EKOLOGI DAN ETNOBOTANI GANDARIA (Bouea macrophylla Griffith)
}

\author{
Tri Harsono \\ Jurusan Biologi FMIPA Unimed, Jl. Willem Iskandar Psr V Medan Estate, Sumatera Utara \\ trihasrsonounimed@gmail.com
}

\begin{abstract}
ABSTRAK
Indonesia dikenal memiliki tingkat keragaman hayati yang tinggi. Keragaman hayati tanaman di Indonesia merupakan potensi yang dapat dikembangkan dan bernilai tinggi. Salah satu tanaman yang berpotensi untuk dikembangkan adalah gandaria. Gandaria merupakan tanaman yang dapat tumbuh tinggi. Sebagai salah satu tanaman asli Indonesia, gandaria dimanfaatkan mulai dari buah, daun, hingga batangnya. Pemanfaatan yang optimal dari tanaman gandaria dapat meningkatkan nilai ekonomis. Secara ekologi, gandaria menyebar mulai dari kawasan pantai hingga dataran tinggi. Gandaria merupakan tumbuhan tropik basah dan dapat tumbuh pada tanah yang ringan dan subur. Gandaria mudah beradaptasi pada lingkungan budidayanya dan merupakan salah satu komoditas buah-buahan tropis yang berpotensi baik.
\end{abstract}

Kata kunci : ekologi, gandaria, tanaman

\section{ECOLOGY REVIEW AND ETHNOBOTANI GANDARIA (Bouea macrophylla Griffith)}

\begin{abstract}
Indonesia is known to have a high level of biodiversity. The biodiversity of plants in Indonesia is a potential that can be developed and high value. One of the plants that have the potential to be developed is gandaria. Gandaria is a plant that can grow high. As one of the native plants of Indonesia, gandaria used from the fruit, leaves, until the trunk. The optimal utilization of gandaria plants can increase the economic value. Ecologically, gandaria spread from the coast to the highlands. Gandaria is a wet tropical plant and can be grown on a mild and fertile soil. Gandaria is easy to adapt to its cultivation environment and is one of the most potent tropical fruits commodities.
\end{abstract}

Keywords : ecology, gandaria, plant

\section{Pendahuluan}

Gandaria (Bouea macrophylla Griffith) adalah satu spesies dari suku Anacardiaceae, yang di beberapa daerah di Indonesia disebut dengan berbagai nama yang berbeda seperti gandaria (Jawa), jatake, gandaria (Sunda), remieu (Gayo), barania (Dayak ngaju), Asam djanar, Kedjauw lepang; Kundang rumania; Ramania hutan; Ramania pipit; Rengas; Tampusu; Tolok burung; Umpas (Kalimantan) dandoriah (Minangkabau), wetes (Sulawesi Utara), Kalawasa, rapo-rapo kebo (Makasar), buwa melawe (Bugis), ma praang, somprang (Thailand). Kundangan, kondongan, gondongan, si kundangan, rumenia, kemenya, rembunia, rumia, setar, serapoh, asam suku, medang asam, gandaria, kundang (Malaysia), Gandaria
(Filipina), Marian-plum (Ingrris) adalah tanaman yang berasal dari kepulauan Indonesia dan Malaysia. Tanaman ini tumbuh di daerah tropis, dan banyak dibudidayakan di Sumatera , Thailand dan Ambon, jadi masih berkisar di kawasan malesiana.

Gandaria dimanfaatkan buah, daun, dan batangnya. Buah gandaria berwarna hijau saat masih muda, dan sering dikonsumsi sebagai rujak atau campuran sambal gandaria. Buah gandaria yang matang berwarna kuning, memiliki rasa kecut-manis dan dapat dimakan langsung. Daunnya digunakan sebagai lalap. Batang gandaria dapat digunakan sebagai papan.

Tanaman gandaria tumbuh dengan habitus pohon dengan ketinggian hingga $27 \mathrm{~m}$ dengan tajuk rapat. Daunnya tunggal, berbentuk bundar 
telur-lonjong sampai bentuk lanset atau jorong Waktu muda berwarna putih, kemudian berangsur ungu tua, lalu menjadi hijau tua. Perbungaannya malai, muncul di ketiak daun, Buahnya bertipe buah batu, berbentuk agak bulat, berdiameter 2,5-5 cm, berwarna kuning sampai jingga, daging buahnya mengeluarkan cairan kental; buahnya tidak berbulu, rasanya asam sampai manis, dengan bau yang khas agak mendekati bau terpentin. Keping biji berwarna lembayung. Gandaria adalah tumbuhan tropik basah dan dapat tumbuh pada tanah yang ringan dan subur. Tumbuh liar di hutan dataran rendah di bawah $300 \mathrm{~m}$ dpl., tetapi dalam pembudidayaan telah berhasil ditanam pada ketinggian sekitar 850 m dpl (Rifai, 1992).

Pembudidayaan gandaria umumnya dilakukan di beberapa lokasi tertentu seperti Jawa Barat, Ambon, Kalimantan dan yang paling banyak melakukan pembudidayaan adalah petani-petani buah dari Thailand. Ditinjau dari nama-nama lokal yang dikenal di Indonesia, Malaysia, maupun Thailand, maka ada lebih kurang 15 nama lokal yang diberikan kepada tanaman ini. Bahkan warga di Kalimantan penduduk setempat membedakannya menjadi ramania pipit dan ramania tembaga yang rasanya manis dan Ramania hintalu yang rasanya asam. Petani-petani di Thailand membedakannya menjadi 3 rasa berdasarkan rasa daging buahnya yaitu ma-prang prew yang rasanya asam, maprang waan atau ma-prang ta it yang rasanya manis dan ma-yong yang rasanya manis pada saat buah matang dan mengandung sedikit asam. Rifai (1992) melaporkan bahwa berdasarkan rasa buahnya, maka di Kalimantan dikenal beberapa kultivar lokal seperti 1. Hintalu (sangat asam). 2. Ramania pipit (manis) 3. Ramania Tembaga (manis). Di Thailand, tanaman ini dikenal dengan Bouea oppositifolia (Roxb.) Meissner yang juga merupakan synonim dari Bouea macrophylla Griffith dan Bouea burmanica Griffith dengan buah yang juga dapat dimakan, tetapi ukurannya lebih kecil dan lebih asam, dikenal dengan nama kultivar lokal ma-praang.

Melihat peluang pengembangan gandaria (Bouea macrophylla Griffith) di masa datang serta masih terbatasnya penelitian dan pembahasan yang dilakukan para ahli botani terhadap salah satu tanaman langka khas Indonesia ini, maka permasalahan yang hendak diulas dalam tulisan berikut ini adalah : (1). Kondisi kondisi ekologi yang berperan dalam menunjang keberadaan gandaria. (2). Etnobotani Gandaria yang ditinjau dari pemanfaatan jenis tumbuhan ini dalam kehidupan sehari-hari.

\section{Bahan dan Metode}

Penulisan naskah tentang gandaria ini dilakukan dengan cara melakukan analisis dan pembahasan tentang gandaria berdasarkan 2 permasalahan yang diajukan dengan menggunakan berbagai sumber data seperti literatur, data-data gandaria yang diakses dari internet, data-data komunikasi pribadi tentang berbagai nara sumber, pengalaman penulis, kaitan satu pengalaman dibandingkan dengan pengalaman lain pada komoditas yang berbeda.

\section{Hasil dan Pembahasan \\ Keberadaan Gandaria di Indonesia}

Gandaria adalah satu tumbuhan asli Indonesia yang termasuk dalam kelompok suku Anacardiaceae. Suku Anacardiaceae masih membawahi beberapa marga yang masih berkerabat dekat dengan Bouea seperti : Anacardium, Androtium, Bouea, Buchanania, Fegimanra, Gluta, Melanorrhoea, Mangifera, Swintonia (Pell, 2004). Gandaria merupakan nama pohon dan buah yang mempunyai nama latin (ilmiah) Bouea macrophylla. Pohon gandaria juga ditetapkan sebagai flora identitas dari provinsi Jawa Barat, mendampingi macan tutul (Panthera pardus) yang ditetapkan sebagai fauna identitas provinsi Jawa Barat. Pohon gandaria (Bouea macrophylla) disebut juga sebagai ramania atau kundangan di beberapa daerah di Indonesia disebut dengan berbagai nama yang berbeda seperti gandaria (Jawa), jatake, gandaria (Sunda), remieu (Gayo), barania (Dayak ngaju), dandoriah (Minangkabau), wetes (Sulawesi Utara), Kalawasa, rapo-rapo kebo (Makasar), buwa melawe (Bugis). (Anonim, 2010, http://alamendah.files.wordpress.com/2010/06) . Banyaknya muncul nama-nama kultivar lokal ini memperlihatkan tingginya pemanfaatan tanaman gandaria dalam kehidupan kelompok etnis di Indonesia. Namun keterbatasan penelitian dan laporan ilmiah mengakibatkan banyak potensinya yang tidak tergarap, bahkan tanaman ini telah dilaporkan sebagai tanaman langka Indonesia (Mogea, et al, 2005).

Gandaria dimanfaatkan mulai dari buah, daun, hingga batangnya. Buah gandaria yang masih muda sering dikonsumsi sebagai rujak atau campuran sambal gandaria. Buah gandaria yang matang dapat dimakan langsung. Daun gandaria sering digunakan sebagai lalap. Sedangkan batang gandaria dapat dimanfaatkan 
sebagai papan dan bahan bangunan. Pada beberapa laporan diketahui bahwa kayu gandaria juga tergolong kayu yang cukup bagus untuk dijadikan sebagai sarung keris, benda pusaka tradisional dalam masyarakat pulau Jawa.

Ciri-ciri dari tanaman gandaria (Bouea macrophylla) mempunyai tinggi hingga mencapai 27 meter. Pohon yang ditetapkan sebagai flora identitas Jawa Barat ini memiliki tajuk yang membulat, rimbun dengan untaian daunnya yang berjuntai. Pohon ini lambat pertumbuhannya. Daun gandaria berbentuk bundar telur memanjang sampai lanset atau jorong. Permukaan daun mengkilat dan mempunyai ujungnya yang runcing. Ukuran daunnya berkisar antara 11- $45 \mathrm{~cm}$ (panjang) dan $4-13 \mathrm{~cm}$ (lebar). Bunga gandaria muncul dari ketiak daun dan berbentuk malai. Bunga berwarna kekuningan yang kemudian berubah kecoklatan. Buah gandaria berbentuk agak bulat dengan diameter antara $2.5-5 \mathrm{~cm}$. Buah gandaria yang masih muda berwarna hijau. Ketika mulai tua dan matang buah berwarna kuning hingga jingga. Buah gandaria memiliki daging buah yang mengeluarkan cairan kental. Buah ini memiliki bau khas yang menyengat dan memiliki rasa agak asam hingga manis.

\section{Ekologi gandaria}

Tanaman gandaria (Bouea macrophylla Griffith) merupakan tumbuhan asli Indonesia yang juga terdapat di semenanjung Malaysia dan Thailand, Selatan China, Indochina, Myanmar, Pulau Andaman. Di Indonesia tanaman ini banyak ditemukan di Sumatera, Jawa, Kalimantan dan Maluku. Pohon gandaria tumbuh di daerah beriklim tropis yang basah. Secara alami, tumbuhan yang menjadi flora identitas provinsi Jawa barat ini tumbuh di daerah dataran rendah hingga pada ketinggian 300 meter dpl. Namun pada tanaman yang dibudidayakan, gandaria mampu tumbuh dengan baik hingga ketinggian 850 meter dpl.

Gandaria menyebar sejak kawasan pantai hingga dataran tinggi. Beberapa sentra pertumbuhan gandaria antara lain Pantai Carita (Jawa Barat). Kota Ambon, Sampit, Banjarmasin (Kalimantan), Padang Bolak (Sumut), Selat Panjang (Riau), dan Thailand. Di Thailand gandaria merupakan buah-buahan pavorit dan pembudidayaannya sudah jauh lebih maju. Di Indonesia, pembudidayaan gandaria masih dilakukan secara sambilan oleh beberapa petani di Ambon. Di Kalimantan dan Sumatera tanaman ini tumbuh liar di kawasan hutan dan tepian hutan. Sedangkan di pulau jawa dilakukan penanaman secara lokal dan ditanam sebagai tanaman sambilan di kebun atau pekarangan rumah.

Gandaria mudah beradaptasi pada lingkungan budidayanya dan merupakan salah satu komoditas buah-buahan tropis yang berpotensi baik, sehingga ditetapkan menjadi flora untuk Provinsi Jawa Barat. Gandaria telah dibudidayakan dalam waktu yang cukup lama dan menjadi bagian dari budaya lokal dimana tumbuhan ini ditemukan, sehingga penyebutan nama tumbuhan ini menjadi beraneka ragam. Penyebutan nama gandaria yang berbeda-beda tersebut merupakan satu cerminan asal usul dan persebarannya. Nama-nama yang diberikan untuk gandaria lebih mengikuti pola penamaan yang berkembang di kawasan Asia Tenggara sesuai dengan daerah dan negara asalnya.

\section{Penamaan lokal gandaria}

Di Asia Tenggara dikenal serangkaian namanama seperti : gandaria, jatake, remieu, barania, asam djanar, kedjauw lepang, kundang rumania, ramania hutan, ramania pipit, rengas, tampusu, tolok burung, Umpas, dandoriah, wetes, Kalawasa, rapo-rapo kebo, buwa melawe, ma praang, somprang, kundangan, kondongan, gondongan, si kundangan, rumenia, kemenya, rembunia, rumia, setar, serapoh, asam suku, medang asam (Heyne, 1927; Rifai, 1992; Rehatta, 2005; ).

Munculnya kerancuan atau perbedaan penamaan gandaria (Bouea macrophylla Griffith) yang menggunakan berbagai kriteria seperti rasa daging buah, atau warna kulit buah matang dimungkinkan oleh plastisitas morfologi yang besar antara kultivar-kultivar gandaria yang ada di sentra pertumbuhannya yang dimungkinkan oleh adanya perkawinan silang antar kultivar, sehingga menghasilkan bentuk-bentuk antara yang sulit dibuat batasan kultivarnya. Di sisi lain untuk tujuan pendayagunaan, pengelolaan dan konservasi plasma nutfah gandaria memerlukan kejelasan nama dan batasan kultivar.

Identifikasi, karakterisasi dan evaluasi kultivar dalam jenis gandaria (Bouea macrophylla Griffith) belum pernah dilakukan, terutama untuk kultivar-kultivar yang ada di Indonesia. Sebagian kultivar yang ada di Kalimantan telah dilakukan identifikasi secara lokal oleh penduduk asli sehingga dikenal adanya hintalu, ramania pipit, ramania tembaga, ramania harang. Adanya pertautan ciri antara kultivar gandaria dan besarnya plastisitas ciri morfologi menjadi salah satu penyebab sulitnya 
dilakukan pembatasan kultivar dalam jenis gandaria, sehingga perlu didukung oleh sumber data dengan pendekatan lain yang lebih komprehensif.

Pemberian nama untuk jenis ini dalam beberapa versi nama lokal memperlihatkan bahwa gandaria merupakan jenis yang dikenal di banyak daerah di sentra produksi kawasan Malesiana. Pemberian nama lokal oleh penduduk setempat ternyata banyak juga yang memiliki arti dan sekaligus memperlihatkan ciri yang berbeda antara satu tanaman dengan tanaman yang lain.

Di Kalimantan tanaman ini dikenal dengan nama ramania. Rifai (1992) melaporkan bahwa berdasarkan rasa daging buahnya dikenal adanya : Ramania pipit yang rasanya manis dan ramania hintalu (Dicirikan dengan bentuk buah yang bundar, besar, warna kulit buah kuning mulus, rasa buahnya yang manis). Selain dua kultivar tersebut, dikenal juga dua nama kultivar lokal lainnya yaitu ramania tembaga dan ramania harang yang dicirikan dengan warna kulit buah kuning berbintik-bintik hitam, berukuran agak kecil. Rasa manis (Saleh dkk, 2005).

Jadi dengan mengacu nama lokal yang diberikan penduduk sudah dapat dipastikan bawah di sana dikenal adanya dua kultivar lokal yang memang sangat berbeda dari segi rasa.

Di Jawa Barat, dikenal dengan nama gandaria atau juga jatake. Namun yang ditemukan di Jawa Barat umumnya terasa asam dan dimanfaatkan pada saat buah masih muda. Pemanfaatannya sebagai sambal gandaria yang merupakan hidangan khas penduduk Jawa Barat yang sangat dikenal. Pemanfaatan gandaria sebagai sambal juga dikenal oleh suku Dayak dan Suku Banjar di Kalimantan. Mereka memanfaatkannya sebagai sambal ramania.

\section{Pemanfaatan gandaria dalam kehidupan}

Gandaria dimanfaatkan mulai dari buah, daun, hingga batangnya. Buah gandaria yang masih muda banyak dimanfaatkan sebagai rujak atau sebagai campuran pada sambal gandaria yang banyak diminati di Jawa Barat (Sunda).

Buah Gandaria yang masih muda dapat pula diramu menjadi rujak Kanistren yang dipergunakan dalam upacara Tebus Wetengan pada saat wanita sunda hamil 7 bulan. Selain dibuat asinan dan sirup buah gandaria yang sudah matang juga dapat dikonsumsi (dimakan) langsung.

Daun gandaria yang masih muda sering kali dimanfaatkan sebagai lalap. Sedangkan batang pohon gandaria bisa digunakan sebagai papan dan bahan bangunan lainnya. Di samping manfaat dari buah, daun, dan batang (kayu) gandaria. Pohon ini juga cocok ditanam di halaman sebagai tanaman peneduh karena memiliki tajuk yang lebat. Kayu tanaman ini dapat digunakan untuk sarung keris dan untuk bahan bangunan. Sebagai tumbuhan perenial yang hidupnya menahun, diperkirakan baru berbuah setelah berumur 8-12 tahun, maka gandaria memiliki banyak hal yang dapat dimanfaatkan dalam kehidupan manusia. Kualitas kayu yang dihasilkan, memang masih tergolong kayu kelas menengah.

Di Jawa barat, tanaman ini sangat dikenal, terutama dengan pemanfaatannya sebagai sambal gandaria. Cara membuat sambal gandaria cukup mudah. Yang dibutuhkan sama dengan bahan-bahan untuk membuat sambal terasi biasa yakni, cabe (merah keriting, campur cabe rawit merah/hijau), terasi (jenis apa saja, tapi saya paling suka terasi Bangka, atau kalau tidak terasi dari \awa Timur), tomat, garam \& gula merah. Cabai dan tomat kita rebus sebentar agar lunak, lalu diulek hingga halus bersama terasi matang (boleh dibakar atau digoreng), garam dan gula merah. Setelah halus, lalu masukkan daging buah gandaria dan ulek kasar. Hidangkan bersama lalapan yang segar.

Kandungan rasa asam pada daging buahnya yang masih muda, dilaporkan sangat merangsang selera makan, apalagi jika dilengkapi dengan produk makanan lainnya seperti ikan bakar, ikan goreng dan lain sebagainya. Rasa asam yang terkandung pada buah muda gandaria diperkirakan akan merangsang kelenjar ludah dibawah telinga (glandula saliva parotis) untuk mengeluarkan sekretnya. Di dalam sistem pencernaan makanan, salah satu fungsi ludah adalah untuk membantu sistem pencernaan makanan. Namun tidak semua rasa asam dapat merangsang kelenjar ludah di bawah telinga untuk menghasilkan sekretnya. Dengan dikeluarkannya sekret dari glandula saliva parotis tersebut, timbul rangsangan untuk makan bagi siapa saja yang mengkonsumsinya. Hal ini sepertinya berkaitan erat dengan penggunaan andaliman Zanthoxylum acanthopodium (Rutaceae) dalam makanan khas Batak yang bernama arsik. Arsik juga merupakan panganan yang sangat merangsang napsu makan orang yang mengkonsumsinya. Diperkirakan kandungan rasa asam pada andaliman yang berperan dalam merangsang sekret glandula saliva parotis untuk keluar (Harsono, 2011). 
Di beberapa sentra produksi Indonesia, buah dari tanaman ini diperdagangkan di sentrasentra perdagangan. Umumnya buah gandaria diperdagnagkan sesuai musimnya. Musim buah matang berkisar antara bulan Desember hingga bulan Februari. Namun ada juga yang dipasarkan dalam keadaan buah muda untuk dijadikan sebagai bahan baku sambal.

Di Kalimantan, suku Dayak dan Suku Banjar juga memanfaatkan Bouea macrophylla Griffith ini sebagai sumber makanan khas daerah. Di Kalimantan gandaria dikenal dengan nama Ramania, dan juga dimanfaatkan sebagai sambal ramania yang sangat cocok dipakai untuk menemani lalapan, ayam, ikan, tahu atau tempe goreng, maupun ikan asin. Cara membuat sambal ini cukup sederhana, yaitu dengan menghaluskan bahan mentah berupa cabe rawit, bawang merah, garam, gula atau MSG sedikit, dan terasi bakar. Bila bahan tersebut sudah halus masukan buah ramania mentah yang diiris dan dimemarkan, aduk sampai merata, siap dihidangkan. Jenis sambal ini dibuat untuk sekali makan. Sambal ini cocok dikombinasikan dengan sayur rebus, lalapan, ikan bakar, ikan goreng, daging maupun sayur berkuah.

Selain dua daerah yang memiliki pendayagunaan gandaria yang sangat khas (Jawa barat dan Kalimantan) , di beberapa lokasi lain yang menjadi sentra produksi buah gandaria, komoditas ini umumnya dimanfaatkan sebagai konsumsi buah segar, dan di beberapa lokasi di kalimantan lebih dikenal dengan buah-buahan hutan, karena tidak dihasilkan lewat penanaman oleh penduduk, tetapi didapatkan dari hutanhutan yang berdekatan dengan lokasi tersebut. Umumnya gandaria yang didapatkan dari hutan rasanya asam, kalaupun terasa manis harus dipetik dalam keadaan yang sangat matang. Selain buahnya, warga lokal memanfaatkan batang tanaman sebagai sumber papan untuk perumahan, perabotan \& kebutuhan lainnya.

\section{Kesimpulan}

Beberapa simpulan dan saran yang dapat diambil berdasarkan analisis dan pembahasan yang dilakukan antara lain :

Keberadaan gandaria di Indonesia Gandaria merupakan nama pohon dan buah yang mempunyai nama latin (ilmiah) Bouea macrophylla. Pohon gandaria juga ditetapkan sebagai flora identitas dari provinsi Jawa Barat.

Gambaran penamaan kultivar gandaria Di Asia Tenggara dikenal serangkaian namanama seperti : gandaria, jatake, remieu, barania, asam djanar, kedjauw lepang, kundang rumania, ramania hutan, ramania pipit, rengas, tampusu, tolok burung, Umpas, dandoriah, wetes, Kalawasa, rapo-rapo kebo, buwa melawe, ma praang, somprang, kundangan, kondongan, gondongan, si kundangan, rumenia, kemenya, rembunia, rumia, setar, serapoh, asam suku, medang asam

Pemanfaatan gandaria dalam kehidupan kelompok etnis di Indonesia Gandaria dimanfaatkan buah, daun, dan batangnya. Buah gandaria berwarna hijau saat masih muda, dan sering dikonsumsi sebagai rujak atau campuran sambal gandaria di Jawa Barat dan sambal ramania di kalimantan. Buah gandaria yang matang berwarna kuning, memiliki rasa kecutmanis dan dapat dimakan langsung. Daunnya digunakan sebagai lalap. Batang gandaria dapat digunakan sebagai papan, perumahan dan perabot. Juga dimanfaatkan sebagai sarung keris.

\section{Daftar Pustaka}

Anonim, 2011. Resep makanan Daerah Kalimantan. ttp://resepmasakandaerahku. blogspot. com/2011/12/sambalramania.html.

Anonim, 2010, Gandaria (Bouea macrophylla) http://alamendah.files.wordpress. com $/ 2010 / 06$

Anonim, 2008, Gandaria, http://id.wikipedia.org/wiki/ Gandaria, 4 Februari 2008

Anonim, 2011. Resep makanan Daerah Kalimantan.

ttp://resepmasakandaerahku. blogspot.com/2011/12/sambalramania.html.

Griffith . 1854. Bouea macrophylla Griff., Pl. Cantor in Journal Asia Soc. Benghal : 23 (1854)

Heyne, K. 1927. De Nuttige Planten Van Netherlands Indie. Vol. 2 967-969. Gedruke by Ruygrok \& Co. Batavia

Meisnerr. 1837. Bouea oppositifolia (Roxb.) Meisn. Pl. vasc. gen. 2:55. 1837

Miquel. 1859. Bouea gandaria Blume ex Miq. Flora. Nedherland Indie 1(2):635. 1859

Pell., S.C. 2004. Molecular Systematics of The Cashew Family (Anacardiaceae). Dissertasion. The Depart. of Biological Sciences. Louisiana State University

Rahayu, M; S. Susiarti DanN Y. Purwanto, 2006. Kajian Pemanfaatan Tumbuhan Hutan Non Kayu oleh Masyarakat Lokal di Kawasan Konservasi PT. Wira Karya Sakti Sungai 
Tapa - Jambi. BIODIVERSITAS ISSN: 1412033X Volume 8, Nomor 1 Januari 2007 Halaman: 73-78

Rifai, M.A., 1992. Bouea macrophylla Griffith. In Coronel, R.E. \& Verheij, E.W.M. (Eds.): Plant Resources of South-East Asia. No. 2: Edible fruits and nuts. Prosea Foundation, Bogor, Indonesia. pp. 104-105.

Rehatta,H. 2005. Potensi dan pengembangan tanaman gandaria (Bouea macro phylla Griffith) di desa Soya Kecamatan Sirimau, Kota Ambon. Laporan Hasil
Penelitian. Lemlit. Universitas Pattimura. Ambon.

Rudini, 1990. Daftar Identitas flora dan fauna daerah. Jakarta. Depdagri.

Saleh, M. Mawardi M., Eddy W. dan D. Hatmoko, 2005. Determinasi Dan Morfologi Buah Eksotis Potensial Di Lahan Rawa. Balai Penelitian Pertanian Lahan Rawa Banjarbaru

Tim Penulis Penebar Swadaya, 1990. Mengenal Tanaman Langka Indonesia, Jakarta: Penebar Swadaya, Cetakan III. 